\title{
Comorbidity in chronic obstructive pulmonary disease. Related to disease severity?
}

This article was published in the following Dove Press journal:

International Journal of COPD

19 November 2014

Number of times this article has been viewed

Jose M Echave-Sustaeta

Lorena Comeche Casanova'

Borja G Cosio 2

Juan Jose Soler-Cataluña ${ }^{3}$

Ricardo Garcia-Lujan'

Xavier Ribera ${ }^{4}$

'Respiratory Department, Hospital Universitario Quirón Madrid, Madrid, Spain; ${ }^{2}$ Respiratory Department, Hospital Universitario Son Espases, Palma de Mallorca, Spain; ${ }^{3}$ Respiratory Department, Hospital Arnau de Vilanova, Valencia, Spain; ${ }^{4}$ Medical Deparment, Boehringer Ingelheim, Barcelona, Spain
Correspondence: Jose M Echave-Sustaeta Hospital Universitario Quirón, Servicio de Neumología, C/Diego de Velázquez I, 28223 Pozuelo de Alarcón, Madrid, Spain $\mathrm{Tel}+34914521917$

$\mathrm{Fax}+34914521903$

Email jmechave.mad@quiron.es
Background and objective: Several diseases commonly co-exist with chronic obstructive pulmonary disease (COPD), especially in elderly patients. This study aimed to investigate whether there is an association between COPD severity and the frequency of comorbidities in stable COPD patients.

Patients and methods: In this multicenter, cross-sectional study, patients with spirometric diagnosis of COPD attended to by internal medicine departments throughout Spain were consecutively recruited by 225 internal medicine specialists. The severity of airflow obstruction was graded using the Global Initiative for Chronic Obstructive Lung Disease (GOLD) and data on demographics, smoking history, comorbidities, and dyspnea were collected. The Charlson comorbidity score was calculated.

Results: Eight hundred and sixty-six patients were analyzed: male 93\%, mean age 69.8 (standard deviation [SD] 9.7) years and forced vital capacity in 1 second 42.1 (SD 17.7)\%. Even, the mean (SD) Charlson score was 2.2 (2.2) for stage I, 2.3 (1.5) for stage II, 2.5 (1.6) for stage III, and 2.7 (1.8) for stage IV ( $P=0.013$ between stage I and IV groups), independent predictors of Charlson score in the multivariate analysis were age, smoking history (pack-years), the hemoglobin level, and dyspnea, but not GOLD stage.

Conclusion: COPD patients attended to in internal medicine departments show high scores of comorbidity. However, GOLD stage was not an independent predictor of comorbidity.

Keywords: Charlson, comorbidity, COPD

\section{Introduction}

Chronic obstructive pulmonary disease (COPD) is characterized by an abnormal inflammatory response of the lungs to noxious particles or gases. ${ }^{1}$ In recent years, increasing attention has been paid to "systemic inflammation" that is often associated with COPD. ${ }^{2-5}$ At the same time there has been a growing recognition that comorbidities such as cardiovascular disease, ${ }^{6-8}$ metabolic syndrome, ${ }^{9}$ cachexia, ${ }^{10}$ anemia, ${ }^{11}$ osteoporosis, ${ }^{12}$ or depression ${ }^{13}$ may be present in a greater proportion of patients with COPD than in the general population. ${ }^{14-16}$ Comorbidities have been reported to have a negative impact on prognosis and survival. ${ }^{17-19}$ A publication describes a systemic phenotype in patients with milder airway obstruction, but higher proportion of obesity, cardiovascular disorders, diabetes mellitus, and systemic inflammation. ${ }^{20}$ This group had more admissions due to cardiovascular disease (hazard ratio [HR] 2.87, $P=0.01)$.

Cigarette smoking is a common risk factor for some of these comorbidities. However, it has been found that, independently of exposure, for every $10 \%$ decrease 
in forced vital capacity in 1 second $\left(\mathrm{FEV}_{1}\right)$, overall mortality increased $14 \%$, cardiovascular mortality by $28 \%$, and coronary complications by at least $20 \%{ }^{21}$ These findings would suggest that COPD airflow severity could be related to the presence of comorbidities.

Many of the studies of comorbidity in patients with COPD come from population databases ${ }^{6,18}$ or cohorts from respiratory medicine departments, ${ }^{22-24}$ even though patients with COPD and other comorbid conditions are currently attended to by other departments such as internal medicine ${ }^{25}$ or cardiology. ${ }^{26}$ Indeed, the fact that patients are attended to by the respiratory medicine department rather than referred to other departments may actually select patients with less severe comorbid conditions. ${ }^{27}$

In the ECLIPSE study, the comorbidities were more prevalent in COPD patients than in controls and occurred to the same extent irrespective of the Global Initiative for Chronic Obstructive Lung Disease (GOLD) stage, ${ }^{15}$ and the comorbidities worsened the prognosis and increased the mortality. ${ }^{16}$ The patients were recruited from respiratory medicine departments and evaluation of comorbidities was not the main objective of the study.

We hypothesized that there is an association between COPD airflow severity and comorbidity, in such a way that to major COPD airflow limitation, major prevalence of comorbidity.

The aims of this study were: 1) to determine the prevalence of comorbid conditions in a large cohort of outpatients with COPD attended to by internal medicine departments, and 2) to investigate whether the comorbidity is related to disease severity.

\section{Patients and methods}

In this observational, cross-sectional multicenter study, patients were enrolled consecutively by 225 internal medicine specialists throughout Spain in an outpatient setting. Patients with COPD diagnosed by spirometry at least 6 months earlier were eligible for inclusion. Subjects must have a smoking history of $\geq 10$ pack-years. Each specialist aimed to enroll five outpatients with a distribution of COPD severity according to the degree of airflow obstruction by GOLD criteria ${ }^{1}$ as follows: one patient with stage I (mild) disease $\left(\mathrm{FEV}_{1} \geq 80 \%\right)$ or stage II (moderate) disease $\left(50 \% \leq \mathrm{FEV}_{1}<80 \%\right)$, two patients with stage III (severe) disease $\left(30 \% \leq \mathrm{FEV}_{1}<50 \%\right)$, and two patients with stage IV (very severe) disease $\left(\mathrm{FEV}_{1}<30 \%\right.$ or $\mathrm{FEV}_{1}<50 \%$ with chronic respiratory failure). This distribution was selected to help ensure compliance with the sample size calculation (see below).
All patients were free from an exacerbation of COPD requiring treatment with corticosteroids or antibiotics in the 4 weeks prior to inclusion.

Strict confidentiality was maintained and all data were analyzed anonymously. All patients signed an informed consent, which included permission to use the data collected to be used in the study. The relevant ethics committee approved the study.

\section{Variables}

For eligible patients, demographic data including smoking habit and data on COPD were collected. Comorbidities were recorded in two different ways, as a predetermined list of 24 diseases (Supplementary material) and as a predefined list of diseases used to calculate the Charlson index (both unadjusted and age-adjusted). ${ }^{25}$ We considered Charlson score of $0-1$ as absence of comorbidity, 2 as low comorbidity and $\geq 3$ as high comorbidity. Anemia was defined as hemoglobin under $13 \mathrm{~g} / \mathrm{dL}$ in men and $12 \mathrm{~g} / \mathrm{dL}$ in women. In addition, dyspnea was assessed using the Medical Research Council dyspnea scale. All COPD treatment and other concomitant medications were recorded.

\section{Sample size}

For comparison of GOLD stage I/II with stage IV, a difference on the Charlson scale of two points was considered relevant. For comparison of stage III and stage IV disease, a one point difference was considered relevant. This would require 200 patients with stage I or II disease, 400 with stage III disease, and 400 with stage IV disease to give mutually exclusive two-sided $95 \%$ confidence intervals (CIs) for these levels with an error of precision less than 0.3 .

\section{Statistical analysis}

Descriptive statistics were calculated for all variables. For comparison of independent data between more than two groups (four COPD stages or between different smoking habits), an analysis of variance (ANOVA) was performed for quantitative variables and the Mantel-Haenszel test for qualitative ones. For comparison of independent data between two groups the Student's $t$-test was used for quantitative variables and the $\chi^{2}$ test for qualitative ones.

The association between study variables and the Charlson score was further examined by undertaking a multiple linear regression analysis. Study variables with a Pearson correlation coefficient with a Charlson score of greater than 0.1 were included as independent variables. 
All statistical tests were two-tailed and significance was set at $5 \%$. They were performed using the SAS statistical package, version 8.2 (SAS Institute Inc., Cary, NC, USA).

\section{Results}

Nine hundred and seventy-seven patients were included, but eventually $111(11 \%)$ who did not meet the criteria of smoking more than ten packs per year, post bronchodilator $\mathrm{FEV}_{1} /$ FVC less than $70 \%$, and present value of the Charlson index were excluded from the analysis. In total, 866 patients were included in the study.

The demographic characteristics of the patients included in the study are summarized in Table 1. There was a statistically significant greater proportion of men, older age, and greater cigarette consumption measured in pack-years with increasing disease severity. No differences were found in body mass index in the different groups of COPD severity. This was a population of patients with a relatively high hospitalization rate the preceding year, and this rate increased significantly with COPD severity.

\section{Univariate analysis}

The mean (standard deviation) unadjusted and age-adjusted Charlson score was 2.5 (1.7) and 5.0 (2.0), respectively, for the overall sample. The score increased significantly with increasing disease severity (Table 2). Charlson scores were significantly different on analysis by the presence or absence of respiratory failure $\left(\mathrm{SaO}_{2}<90 \%\right)(2.7$ [1.8] versus 2.4 [1.6], $P=0.003$ ).

The most common comorbidity across all groups of COPD severity was arterial hypertension $(57.1 \%$ of the sample) followed by hypercholesterolemia (33.3\%) and diabetes mellitus (31.1\%). An overview of the most frequently reported metabolic and cardiovascular comorbidities is given in Table 3. Conditions that show an association with COPD airflow limitation severity were hypercholesterolemia, diabetes mellitus, heart failure, and atrial fibrillation.

Other frequently reported comorbidities like cataracts (21.1\% of the sample), arthrosis (19.3\%), anxiety (14.3\%), and depression $(11.1 \%)$ did not show an association with COPD severity.

Obstructive sleep apnea was reported in $10.6 \%$ of the overall sample, with no significant differences according to GOLD stage: $(P=0.64): 5 \%$ in GOLD I, $11.7 \%$ in GOLD II, $10.9 \%$ in GOLD III, and $9.8 \%$ in GOLD IV.

Anemia was reported in $26 \%$ of the overall sample but no significant association was found between COPD severity and presence of anemia $(P=0.07)$. However, anemia was more prevalent in patients with greater comorbidity as measured by the Charlson index $(P<0.001)$ (Table 4$)$. When patients with renal failure, digestive disease, hepatic disease and cancer were excluded, the prevalence was $21.6 \%$.

Cancer was reported in $92 / 866$ patients $(10.6 \%)$ in the overall sample, with no significant differences according to GOLD stage. The body system most frequently affected was the respiratory system, accounting for 17 of the 92 patients with malignancies (18.5\%). All 17 of these patients with lung cancer belonged to GOLD stage III or IV.

Pneumonia in the previous 12 months increased significantly according to GOLD stage $(P=0.02): 7 \%$ in GOLD I, $7.8 \%$ in GOLD II, $11.6 \%$ in GOLD III, and $17.0 \%$ in GOLD IV. These effects were also observed when excluding

Table I Demographic characteristics

\begin{tabular}{|c|c|c|c|c|c|}
\hline GOLD stage & $\begin{array}{l}\text { Stage I } \\
N=43\end{array}$ & $\begin{array}{l}\text { Stage II } \\
N=167\end{array}$ & $\begin{array}{l}\text { Stage III } \\
N=362\end{array}$ & $\begin{array}{l}\text { Stage IV } \\
\mathbf{N}=294\end{array}$ & $\begin{array}{l}\text { Total } \\
\mathbf{N}=866\end{array}$ \\
\hline Sex ${ }^{\mathrm{b}}$ male (\%) & $38(88.4)$ & 136 (8I.4) & $328(90.6)$ & 256 (87.1) & $758(87.5)$ \\
\hline Age, years $(S D)^{b}$ & $65.9(10.2)$ & $68.0(10.9)$ & $70.1(9.4)$ & $70.9(9.01)$ & $69.8(9.7)$ \\
\hline BMI, $\mathrm{kg} / \mathrm{m}^{2}$ & $28.0(4.3)$ & $27.0(4.2)$ & $28.0(4.8)$ & $27.0(4.6)$ & $27.5(4.6)$ \\
\hline \multicolumn{6}{|l|}{ Smoking status ${ }^{\mathrm{b}}$} \\
\hline Ex-smoker & $29(67.4 \%)$ & 119 (7I.3\%) & 287 (79.2\%) & 238 (80.9\%) & 673 (77.8\%) \\
\hline Smoker & $14(32.6 \%)$ & $48(28.7 \%)$ & $75(20.8 \%)$ & $56(19.1 \%)$ & $193(22.2 \%)$ \\
\hline Pack-years (interquartile range) ${ }^{\mathrm{a}, \mathrm{c}}$ & $30.0(22.5 / 45.0)$ & $36.0(20.0 / 51.0)$ & $40.5(28.4 / 60.0)$ & $48.0(31.3 / 67.5)$ & $41.3(30.0 / 60.0)$ \\
\hline Dyspnea $(M R C)^{c}$ & $\mathrm{I} .0(0.7)$ & $\mathrm{I} .2(0.9)$ & $2.3(0.9)$ & $3.2(0.9)$ & $2.3(1.2)$ \\
\hline $\mathrm{FEV}_{1}, \%$ predicted $^{\mathrm{c}}$ & $85.2(5.7)$ & $63.7(8.7)$ & $40.4(5.9)$ & $25.6(4.1)$ & $42.1(17.7)$ \\
\hline $\mathrm{SaO}_{2}, \%$ & $92.6(4.0)$ & $91.3(7.3)$ & $89.6(6.6)$ & $85.9(8.8)$ & $89.1(7.8)$ \\
\hline $\begin{array}{l}\text { No of days in hospital for any cause during } \\
\text { previous } 12 \text { months (interquartile range) }{ }^{a, b}\end{array}$ & $8.0(7.0 / 16.0)$ & $12.0(8.0 / 24.0)$ & $12.5(8.0 / 26.0)$ & $20.0(10.0 / 37.0)$ & I $5.0(8.0 / 29.0)$ \\
\hline
\end{tabular}

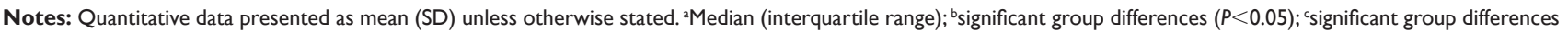
$(P<0.001)$.

Abbreviations: BMI, body mass index; FEV , forced vital capacity in I second; GOLD, Global Initiative for Chronic Obstructive Lung Disease; MRC, Medical Research Council; SD, standard deviation. 
Table 2 Charlson index according to COPD severity

\begin{tabular}{|c|c|c|c|c|c|}
\hline & $\begin{array}{l}\text { Stage I } \\
\mathbf{N}=43\end{array}$ & $\begin{array}{l}\text { Stage II } \\
N=167\end{array}$ & $\begin{array}{l}\text { Stage III } \\
N=362\end{array}$ & $\begin{array}{l}\text { Stage IV } \\
\mathbf{N}=294\end{array}$ & $\begin{array}{l}\text { Total } \\
\mathbf{N}=866\end{array}$ \\
\hline Charlson score ${ }^{a}$ & $2.2(2.2)$ & $2.3(1.5)$ & $2.5(1.6)$ & $2.7(1.8)$ & $2.5(1.7)$ \\
\hline \multicolumn{6}{|c|}{ Comorbidity according to Charlson score } \\
\hline No $(\text { score } \leq \mathrm{I})^{\mathrm{a}}$ & $2 \mathrm{I}(46.5 \%)$ & $74(44.4 \%)$ & II 5 (3I.8\%) & $93(31.5 \%)$ & $303(35.0 \%)$ \\
\hline Mild (score $=2$ ) & $14(34.9 \%)$ & $40(23.9 \%)$ & $107(30.1 \%)$ & $66(22.5 \%)$ & $227(26.2 \%)$ \\
\hline High (score $\geq 3)^{\mathrm{a}}$ & $8(18.6 \%)$ & $53(31.7 \%)$ & 140 (38. I\%) & I 35 (46\%) & $336(38.8 \%)$ \\
\hline
\end{tabular}

Note: aSignificant group differences $(P<0.05)$ according to Mantel-Haenszel test.

Abbreviation: COPD, chronic obstructive pulmonary disease.

the patients who were receiving regular treatment with inhaled corticosteroids $(P<0.001)$ : $5 \%$ in GOLD I, $5.6 \%$ in GOLD II, $11.6 \%$ in GOLD III, and $18.6 \%$ in GOLD IV.

\section{Multivariate analysis}

To clarify whether severity of airflow obstruction (measured by GOLD stage) and comorbidity (measured by the Charlson index) were independently related, a multivariate regression analysis (Table 5) was performed. Variables with a Pearson correlation coefficient greater than \pm 0.1 that did not show multicollinearity (COPD severity, age, pack-years, hemoglobin levels, and presence of dyspnea according to the Medical Research Council definition) and the Charlson score as the dependent variable were included in the analysis. COPD severity was not significantly associated with Charlson score $(P=0.13)$ although a significant association remained for age $(P<0.001)$, pack-years $(P=0.03)$, hemoglobin level $(P<0.001)$, and dyspnea $(P=0.04)$. The coefficient of determination (R2) was 0.11 .

\section{Discussion}

In this study, we investigated the relationship between comorbidities and COPD airflow limitation severity as determined by GOLD staging in patients attended to consecutively as outpatients by internal medicine departments. We found that COPD patients frequently suffer from comorbid conditions although the frequency of these comorbidities according to
Charlson index, were not directly related to COPD severity. Age, anemia, pack-years of smoking, and dyspnea were indeed independently associated with comorbidity.

Comparisons between epidemiological studies of comorbidities in COPD face a number of difficulties. For example, retrospective population studies of mortality from hospital records or death certificates may underestimate the contribution of COPD because it is not always recorded as a comorbid condition when it is present. To reduce underdiagnosis of comorbidities the data were collected from medical history and after a prospective interview with the patient. Likewise, a universal definition of COPD has not always been applied, although the use of GOLD criteria based on spirometry is now becoming widespread and is considered the "gold standard". ${ }^{1}$ An important aspect of our study was that only patients with COPD confirmed by spirometry were included in the sample. In addition, unlike previous studies, our study includes patients with all the stages of severity, from mild to very severe.

In a study investigating the value of the 6 minute walk distance for predicting mortality, Pinto-Plata et a ${ }^{22}$ recruited patients with COPD (mean $\mathrm{FEV}_{1}, 1.04$ [0.39], comparable to stage III patients in our study) from pulmonary departments of two hospitals. The authors reported an age-adjusted Charlson score of 4.29 for patients who survived until the end of follow-up, and 4.14 and 4.19 for those who survived for one and two assessments, respectively. These values are

Table 3 Metabolic and cardiovascular comorbidities according to COPD severity

\begin{tabular}{|c|c|c|c|c|c|}
\hline Disease & $\begin{array}{l}\text { Stage I } \\
N=43\end{array}$ & $\begin{array}{l}\text { Stage II } \\
N=167\end{array}$ & $\begin{array}{l}\text { Stage III } \\
\mathrm{N}=362\end{array}$ & $\begin{array}{l}\text { Stage IV } \\
\mathbf{N}=294\end{array}$ & $\begin{array}{l}\text { Total } \\
\mathrm{N}=866\end{array}$ \\
\hline Hypertension & $34(79.1 \%)$ & $90(53.9 \%)$ & 200 (55.2\%) & I7I (58.2\%) & 495 (57.1\%) \\
\hline Hypercholesterolemia ${ }^{a}$ & $24(55.8 \%)$ & $63(37.7 \%)$ & $111(30.6 \%)$ & $90(30.6 \%)$ & $288(33.2 \%)$ \\
\hline Diabetes $^{\mathrm{a}}$ & $6(13.9 \%)$ & $42(25.1 \%)$ & $122(33.7 \%)$ & $100(34.0 \%)$ & $270(31.2 \%)$ \\
\hline Heart failure ${ }^{a}$ & $5(11.6 \%)$ & $22(13.2 \%)$ & $86(23.7 \%)$ & $86(29.2 \%)$ & 199 (23.0\%) \\
\hline Atrial fibrillation ${ }^{\mathrm{a}}$ & $2(4.6 \%)$ & $22(13.2 \%)$ & $68(18.7 \%)$ & 73 (24.8\%) & 165 (19.0\%) \\
\hline Peripheral vascular disease & $6(13.9 \%)$ & $22(13.2 \%)$ & $68(18.8 \%)$ & $54(18.3 \%)$ & $150(17.3 \%)$ \\
\hline Ischemic heart disease & $10(23.3 \%)$ & $\mathrm{I} 7(\mathrm{I} 0.2 \%)$ & $68(18.8 \%)$ & $47(15.9)$ & $142(16.4 \%)$ \\
\hline
\end{tabular}

Note: aSignificant group differences $(P<0.05)$ according to Mantel-Haenszel test.

Abbreviation: COPD, chronic obstructive pulmonary disease. 
Table 4 Anemia according to Charlson index (Chl)

\begin{tabular}{lllll}
\hline Anemia & $\begin{array}{l}\text { No } \\
\text { comorbidity: } \\
\text { Chl } \leq \mathbf{l}\end{array}$ & $\begin{array}{l}\text { Low } \\
\text { comorbidity: } \\
\text { Chl =2 }\end{array}$ & $\begin{array}{l}\text { High } \\
\text { comorbidity: } \\
\text { Chl } \geq \mathbf{3}\end{array}$ & P-value \\
\hline $\mathrm{n}$ & 282 & 22 I & 334 & \\
No & $247(87.5 \%)$ & $169(76.4 \%)$ & $203(60.7 \%)$ & $<0.00$ I \\
Yes & $35(12.5 \%)$ & $52(23.6 \%)$ & $131(39.2 \%)$ & \\
\hline
\end{tabular}

somewhat lower than the ones reported in our study (5.0 [2.0] for patients with stage III disease). Another prospective study investigating the effect of sex on the clinical expression of COPD patients (mostly with stage II [47\%] or stage III [45\%] disease) seen in a pulmonary clinic reported an age-adjusted Charlson score of 4 for men and 2 for women, ${ }^{23}$ whereas our mean age-adjusted Charlson scores were 5.1 (for men) and 4.6 (for women). In another study of mortality in COPD patients, Marti et al ${ }^{24}$ retrospectively reviewed the records of patients receiving long-term oxygen therapy (mean age, 69 years; $\mathrm{FEV}_{1}, 25 \%$ ). Even though comorbidity measured by the Charlson score was a predictor of all-cause mortality, the percentage of patients in that study with a Charlson score $\geq 2$ was only $14 \%$ compared to $66 \%$ in our study.

Notwithstanding the difficulties of comparison, these studies would seem to suggest that in patients where the focus is on the respiratory aspect of their disease, the Charlson score is lower than when patients are treated by internal medicine specialists.

On the other hand, studies with prospective data collection are susceptible to selection bias. Clearly patients with stable disease recruited in a primary care day clinic are likely to be less ill than hospitalized patients suffering from a COPD exacerbation. Likewise, it might be expected that patients attended to by internal medicine departments would be more likely to suffer from comorbidities than those attended to by pulmonology departments.

For a meaningful discussion on selection biases resulting from patients attended to by pulmonology departments

Table 5 Multiple linear regression analysis with the Charlson score as the dependent variable and including variables with a Pearson correlation coefficient greater than \pm 0 .I

\begin{tabular}{lllll}
\hline Variable & $\begin{array}{l}\text { Parameter } \\
\text { estimate }\end{array}$ & $\begin{array}{l}\text { Standard } \\
\text { error }\end{array}$ & $\boldsymbol{t}$ value & $\boldsymbol{P}$-value $>|\boldsymbol{t}|$ \\
\hline COPD severity & 0.11329 & 0.07509 & 1.51 & 0.1318 \\
Age & 0.02922 & 0.00660 & 4.43 & $<0.0001$ \\
Pack-years & 0.00519 & 0.00238 & 2.17 & 0.0300 \\
Dyspnea & 0.60459 & 0.29706 & 2.04 & 0.0422 \\
Hemoglobin & -0.01746 & 0.00323 & -5.41 & $<0.0001$ \\
\hline
\end{tabular}

Abbreviation: COPD, chronic obstructive pulmonary disease. or internal medicine departments, data would be needed on the profile of patients admitted to one type of department or the other. The only study we could find on the subject was performed in 32 hospitals in Andalusia, Spain. ${ }^{25}$ The investigators examined the hospital records of patients hospitalized for COPD exacerbations and found that $57 \%$ of the patients with a diagnosis of COPD were admitted to internal medicine departments, $31 \%$ to pulmonology departments, and $12 \%$ to other services. They found that women, older patients, patients with diabetes mellitus, heart failure, ischemic heart disease, and supraventricular arrhythmia were more likely to be admitted to internal medicine departments while active or former smokers, patients with pneumonia, and sleep disorders were more likely to be admitted to pulmonology departments. The study by San Román-Terán et $\mathrm{al}^{25}$ would therefore suggest that, in the case of exacerbations at least, patients with prominent comorbidity are less likely to be admitted to pulmonology departments. The fact that the Charlson score in our study was higher than scores reported for samples drawn from pulmonology departments and the generally higher age of our patients would support this finding.

Agusti et al have recently published a study that came to the same conclusions than our work: comorbidities occurred to the same extent irrespective of the GOLD stage..$^{15}$ In fact in our study, the univariate analysis Charlson score increased significantly with increasing disease severity (Table 2), but in the multivariate regression analysis, COPD severity was not significantly associated with Charlson score (Table 5). Both studies have important methodological differences between them. In our study unlike theirs, the measurement of comorbidities in relation to the severity of COPD was the main objective, comorbidities were recorded as a predetermined list of 24 diseases (Supplementary material) and as a predefined list of diseases used to calculate the Charlson index, participating investigators had full access to the patients' medical records and patients were recruited from internal medicine departments. For example, in relation with this latest point, in Agusti's study the prevalence of diabetes mellitus was $10 \%$ and heart failure $7 \%$, versus $31 \%$ and $23 \%$ in ours.

On examination by individual comorbid conditions, arterial hypertension was found to be the most common comorbidity, followed by hypercholesterolemia and diabetes mellitus - all risk factors for heart disease. This would fit with a number of other studies that have underlined the high prevalence of concurrent cardiovascular disease and risk factors in patients with COPD, regardless of how the study sample was drawn. ${ }^{6-8,14,19,21,28}$ In our study, although arterial 
hypertension itself did not appear to be associated with more advanced disease, the prevalence of hypercholesterolemia, diabetes mellitus, heart failure, and atrial fibrillation were all associated with GOLD stage.

Another important comorbidity in patients with COPD is sleep apnea syndrome, because although its prevalence is similar as in the general population, the consequences are worse in patients with COPD. The prevalence of symptomatic sleep apnea syndrome in the general population is estimated at about $6 \%$, but increases with age. In our sample, $10.6 \%$ of patients with COPD presented a syndrome of associated sleep apnea, and the frequency did not increase with the severity of COPD. This last point, as far as we know, has not been studied previously. ${ }^{29,30}$

We found an increased risk of pneumonia according to COPD severity, and this effect was also seen in patients who have not been using inhaled corticosteroids. This is in line with a recently published study, ${ }^{31}$ which found an increased risk of hospitalization due to pneumonia in patients with GOLD stage II disease (HR: 2.25 [95\% CI: 1.35-3.75]) and GOLD stage III-IV disease (HR: 5.65 [95\% CI: 3.29-9.67]), and with a post hoc analysis of the TORCH study ${ }^{32}$ which found an increased risk of pneumonia in patients with $\mathrm{FEV}_{1}<50 \%$ predicted.

Another point of particular interest is the fact that all patients with lung cancer had severe or very severe COPD. This supports the fact that the presence of COPD is a risk factor for lung cancer among smokers. ${ }^{33}$

In any epidemiological study, it is very hard to determine cause and effect. There was a clear increase in the Charlson score with increasing disease severity. The differences between groups were significant, but when a multivariate analysis was undertaken with Charlson score as the dependent variable, COPD severity was not independently associated with Charlson score, whereas age, pack-years, hemoglobin, and dyspnea were. This would be consistent with the idea that while $\mathrm{FEV}_{1}$ is important for staging the disease itself, other factors are significant for determining disease prognosis. ${ }^{34}$

We used the Charlson index as most of the studies, up to now. A recent publication proposes a new index, the COPD specific comorbidity test (COTE), it was constructed based on the comorbidities that increase mortality risk using a multivariate analysis. It is another tool that helps assess mortality risk in patients with COPD. ${ }^{35}$

This study has the limitation that the Charlson index quantifies the degree of comorbidity, but leaves out important comorbidities. Possibly the best approach would be individualized analysis, which is beyond the ambit of the study.
In conclusion, although the importance of comorbidities in COPD patients has been previously stressed in selected respiratory cohorts, we have found that, in a real-life population followed in an internal medicine out-patient clinic, these comorbidities are not directly determined by the severity of COPD, but by other independent prognostic factors such as pack-years, dyspnea, hemoglobin, and age. These findings, together with the variety of treatments associated with each comorbid condition, should be taken carefully into account when approaching the treatment of a COPD patient.

\section{Disclosure}

The authors have no conflicts of interest to disclose in this work. This work was partially funded by Boehringer Ingelheim.

\section{References}

1. goldcopd.org [homepage on the Internet]. Global Strategy for Diagnosis, Management, and Prevention of COPD. Available from: http://www. goldcopd.org/guidelines-global-strategy-for-diagnosis-management. html. Accessed September 21, 2014.

2. Agusti AG, Noguera A, Sauleda J, Sala E, Pons J, Busquets X. Systemic effects of chronic obstructive pulmonary disease. Eur Respir $J$. 2003;21(2):347-360.

3. Gan WQ, Man SF, Senthilselvan A, Sin DD. Association between chronic obstructive pulmonary disease and systemic inflammation: a systematic review and a meta-analysis. Thorax. 2004;59(7):574-580.

4. Barnes PJ, Celli BR. Systemic manifestations and comorbidities of COPD. Eur Respir J. 2009;33(5):1165-1185.

5. Fabbri LM, Luppi F, Beghe B, Rabe KF. Complex chronic comorbidities of COPD. Eur Respir J. 2008;31(1):204-212.

6. Mannino DM, Thorn D, Swensen A, Holguin F. Prevalence and outcomes of diabetes, hypertension and cardiovascular disease in COPD. Eur Respir J. 2008;32(4):962-969.

7. Feary JR, Rodrigues LC, Smith CJ, Hubbard RB, Gibson JE. Prevalence of major comorbidities in subjects with COPD and incidence of myocardial infarction and stroke: a comprehensive analysis using data from primary care. Thorax. 2010;65(11):956-962.

8. Soriano JB, Rigo F, Guerrero D, et al. A. High prevalence of undiagnosed airflow limitation in patients with cardiovascular disease. Chest. 2010;137(2):333-340.

9. Watz H, Waschki B, Kirsten A, et al. The metabolic syndrome in patients with chronic bronchitis and COPD: frequency and associated consequences for systemic inflammation and physical inactivity. Chest. 2009;136(4):1039-1046.

10. Agustí AG, Sauleda J, Miralles C, et al. Skeletal muscle apoptosis and weight loss in chronic obstructive pulmonary disease. Am J Respir Crit Care Med. 2002;166(4):485-489.

11. Shorr AF, Doyle J, Stern L, Dolgister M, Zilberberg MD. Anemia in chronic obstructive pulmonary disease: epidemiology and economic implications. Curr Med Res Opin. 2008;24(4):1123-1130.

12. Jorgensen NR, Schwarz P, Holme I, Henriksen BM, Petersen LJ, Backer V. The prevalence of osteoporosis in patients with chronic obstructive pulmonary disease: a cross sectional study. Respir Med. 2007;101(1):177-185.

13. Julian LJ, Gregorich SE, Earnest G, et al. Screening for depression in chronic obstructive pulmonary disease. COPD. 2009;6(6):452-458.

14. Soriano JB, Visick GT, Muellerova H, Payvandi N, Hansell AL. Patterns of comorbidities in newly diagnosed COPD and asthma in primary care. Chest. 2005;128(4):2099-2107. 
15. Agusti A, Calverley PM, Celli B, et al. Characterisation of COPD heterogeneity in the ECLIPSE cohort. Respir Res. 2010;11:122.

16. Rabe KF, Wedzicha JA, Wouters EF, editors. European Respiratory Society Monograph, COPD and Comorbidity. European Respiratory Society; 2013.

17. Miller J, Edwards LD, Agustí A, et al. Comorbidity, systemic inflammation and outcomes in the ECLIPSE cohort. Respir Med. 2013;107(9):1376-1384.

18. Holguin F, Folch E, Redd SC, Mannino DM. Comorbidity and mortality in COPD-related hospitalizations in the United States, 1979 to 2001. Chest. 2005;128(4):2005-2011.

19. Antonelli Incalzi R, Fuso L, De Rosa M, et al. Co-morbidity contributes to predict mortality of patients with chronic obstructive pulmonary disease. Eur Respir J. 1997;10(12):2794-2800.

20. Garcia-Aymerich J, Gómez FP, Benet M, et al. PAC-COPD Study Group. Identification and prospective validation of clinically relevant chronic obstructive pulmonary disease (COPD) subtypes. Thorax. 2011;66(5):430-437

21. Sin DD, Wu L, Man SF. The relationship between reduced lung function and cardiovascular mortality: a population-based study and a systematic review of the literature. Chest. 2005;127(6):1952-1959.

22. Pinto-Plata VM, Cote C, Cabral H, Taylor J, Celli BR. The 6-min walk distance: change over time and value as a predictor of survival in severe COPD. Eur Respir J. 2004;23(1):28-33.

23. de Torres JP, Casanova C, Hernández C, Abreu J, Aguirre-Jaime A, Celli BR. Gender and COPD in patients attending a pulmonary clinic. Chest. 2005;128(4):2012-2016.

24. Marti S, Muñoz X, Rios J, Morell F, Ferrer J. Body weight and comorbidity predict mortality in COPD patients treated with oxygen therapy. Eur Respir J. 2006;27(4):689-696.

25. San Román-Terán CM, Guijarro R, Gómez-Huelgas R, Montero-Ribas L. Epidemiología hospitalaria de la EPOC en España. Rev Clin Esp. 2007;207(1):3-7. Spanish.
26. Havranek EP, Masoudi FA, Westfall KA, Wolfe P, Ordin DL, Krumholz HM. Spectrum of heart failure in older patients: results from the National Heart Failure project. Am Heart $J$. 2002;143(3):412-417.

27. Charlson ME, Pompei P, Ales KL, MacKenzie CR. A new method of classifying prognostic comorbidity in longitudinal studies: development and validation. J Chronic Dis. 1987;40(5):373-383.

28. Sin DD, Anthonisen NR, Soriano JB, Agusti AG. Mortality in COPD: Role of comorbidities. Eur Respir J. 2006;28(6):1245-1257.

29. Lloberes P, Durán-Cantolla J, Martínez-García MA, et al. Diagnosis and treatment of sleep apnea-hypopnea syndrome. Spanish Society of Pulmonology and Thoracic Surgery. Arch Bronconeumol. 2011;47(3): $143-156$.

30. McNicholas W, Verbraecken J, Marin JM. Sleep disorders in COPD: the forgotten dimension. Eur Respir Rev. 2013;22(129):365-375.

31. Mannino DM, Davis KJ, Kiri VA. Chronic obstructive pulmonary disease and hospitalizations for pneumonia in a US cohort. Respir Med. 2009;103(2):224-229.

32. Crim C, Calverley PM, Anderson JA, et al. Pneumonia risk in COPD patients receiving inhaled corticosteroids alone or in combination: TORCH study results. Eur Respir J. 2009;34(3):641-647.

33. Raviv S, Haekins KA, DeCamp MM Jr, Kalhan R. Lung cancer in chronic obstructive pulmonary disease: enhancing surgical options and outcomes. Am J Respir Crit Care Med. 2011;183(9):1138-1146.

34. Celli BR, Cote CG, Marin JM, et al. The body-mass index, airflow obstruction, dyspnea, and exercise capacity index in chronic obstructive pulmonary disease. $N$ Engl J Med. 2004;350(10):1005-1012.

35. Divo M, Cote C, De Torres JP, et al. BODE Collaborative Group Comorbidities and risk of mortality in patients with chronic obstructive pulmonary disease. Am J Respir Crit Care Med. 2012;186(2): $155-161$. 


\section{Supplementary material}

1. Cataract

2. Glaucoma

3. Ischemic heart disease

4. Heart failure

5. Atrial fibrillation

6. Other arrhythmias

7. Stroke

8. Dementia

9. Peripheral vascular disease

10. Pneumonia

11. Sleep apnea syndrome

12. Peptic ulcer disease
13. Liver disease

14. Arterial hypertension

15. Hypercholesterolemia

16. Diabetes mellitus

17. Fractures

18. Osteoporosis

19. Arthrosis

20. Cancer

21. Anxiety

22. Depression

23. Kidney disease

24. Anemia

\section{Publish your work in this journal}

The International Journal of COPD is an international, peer-reviewed journal of therapeutics and pharmacology focusing on concise rapid reporting of clinical studies and reviews in COPD. Special focus is given to the pathophysiological processes underlying the disease, intervention programs, patient focused education, and self management protocols.
This journal is indexed on PubMed Central, MedLine and CAS. The manuscript management system is completely online and includes a very quick and fair peer-review system, which is all easy to use. Visit http://www.dovepress.com/testimonials.php to read real quotes from published authors. 